\title{
DRY SLIDING FRICTION AND WEAR RESPONSE OF WC-CO HARDMETAL PAIRS IN LINEARLY RECIPROCATING AND ROTATING CONTACT
}

\author{
Y. Perez Delgado ${ }^{1}$, K. Bonny ${ }^{1}$, P. De Baets ${ }^{1}$, P.D. Neis ${ }^{1}$, V. Rodriguez Fereira ${ }^{1}$, O. Malek ${ }^{2,3}$, J. \\ Vleugels ${ }^{2}$, B. Lauwers ${ }^{3}$ \\ ${ }^{1}$ Ghent University, Laboratory Soete, Belgium \\ ${ }^{2}$ Catholic University of Leuven, Metallurgy and Materials Engineering Department, Belgium \\ ${ }^{3}$ Catholic University of Leuven, Mechanical Engineering Department, Belgium
}

\begin{abstract}
This paper presents an experimental evaluation of friction and wear properties of WC-Co cemented carbides. A comparison is made between unlubricated rotating and linearly reciprocating pin-onplate sliding pairs. The plate specimens were WC-10wt\%Co grades surface finished by polishing or sequential wire-EDM steps, whereas WC-6wt\%Co pins were used as counter body. The tests were carried out at room temperature using a sliding speed of $0.30 \mathrm{~m} / \mathrm{s}$ and mean Hertzain contact pressures of 1.76 and $2.08 \mathrm{GPa}$, i.e., normal contact loads of $15 \mathrm{~N}$ and $25 \mathrm{~N}$, respectively. The worn surfaces on plate samples were quantified in terms of 2-D wear profiles obtained by means of surface topography scanning equipment. Wear mechanisms such as polishing and abrasion were identified using optical microscopy. Inferior tribological characteristics for wire-EDM surface finish compared to polishing were found. Higher friction coefficient and wear levels were measured in unidirectional rotating sliding experiments compared to linearly reciprocating test conditions.
\end{abstract}

Keywords friction and wear, wire-EDM, wear particles, reciprocating and rotating sliding contact.

\section{INTRODUCTION}

Inspired by economical and especially ecological motives, engineers have developed new or improved materials able to operate in harsh environments, e.g., high temperature, unlubricated contact, abrasive or erosive circumstances, corrosive surroundings, etc. to which machine elements (gears, brakes, bearings, etc.) and tools ( punches, dies, cutting tools, etc.) are often exposed. Currently, hardmetals are widely used for those applications due to their excellent mechanical properties having unique combination of high hardness, strength, resistance to compressive deformation, wear and corrosion resistance at high temperatures [1]. Cobalt (Co) is the most preferred binder in WC-based hardmetals due to its outstanding wetting and adhesion characteristics in combination with tungsten carbide (WC), leading to unique properties [2]. Nevertheless, some disadvantages such as high hardness make it intrinsically difficult to shape by means of traditional machining techniques such as grinding with boron nitride and/or diamond. Electrical Discharge Machining (EDM) allows the production of complex shapes. However, this machining process could degrade the surface quality in consequence of mechanical and thermal impact. Some research has already been performed on the effects of wire-EDM on friction and wear behaviour of WC-Co cemented carbides in reciprocating sliding contact [3-5]. A problem, however, is the lack of knowledge of tribological behaviour of WC-10wt\%Co cemented carbide on continuous unidirectional rotating sliding contact.

This paper aims to evaluate and compare the friction and wear response of cemented carbides in reciprocating and rotating sliding contact, and examines how the tribological characteristics are affected by the geometry of the sliding motion (linearly reciprocating or unidirectionally rotating), interaction of wear particles, contact loading and surface finish. 


\section{EXPERIMENTAL PROCEDURE}

The WC-10wt\%Co cemented carbide was produced by liquid phase sintering. The physical and mechanical properties of WC-10wt\%Co are listed in Table 1 as a function of chemical and microstructural features. The Vickers hardness was measured with indentation weights of $10 \mathrm{~kg}$ (Model FV-700, Future-Tech Corp., Tokyo, Japan). The grain size distribution was acquired using computer analysis software by the linear intercept method. The fracture toughness, $\mathrm{KIC}, 10 \mathrm{~kg}$, was obtained by Vickers indentation using the formula of Shetty [6]. The Young's modulus, E, was obtained by the resonance frequency method (ASTM C 125994) on a Grindo-sonic (J.W. Lemmens, Elektronika N.V., Leuven, Belgium). The electrical resistivity was obtained by the 4-point contact method using a Resistomat Mikroohmmeter (Type 2302, Gernsbach, Germany).

Table 1. Chemical, microstructural, mechanical and physical properties of WC-10wt\%Co cemented carbide.

\begin{tabular}{|c|c|c|c|c|c|c|c|c|}
\hline Chemical properties & \multicolumn{3}{|c|}{ Microstructure } & \multicolumn{2}{|c|}{ Mechanical properties } & \multirow[b]{2}{*}{$\begin{array}{c}E \text {-modulus } \\
{[\mathrm{GPa}]} \\
\end{array}$} & \multicolumn{2}{|c|}{ Physical properties } \\
\hline Binder amount & $\begin{array}{l}\text { av } \\
{[\rightarrow \mathrm{m}]} \\
\end{array}$ & $\begin{array}{l}d 50 \\
{[\rightarrow \mathrm{m}]} \\
\end{array}$ & $d 90$ & $\begin{array}{c}\mathrm{HV}_{10} \\
{\left[\mathrm{~kg} / \mathrm{mm}^{2}\right]}\end{array}$ & $\begin{array}{c}K \mathrm{IC}(10 \mathrm{~kg}) \\
{[\mathrm{Mpa}} \\
\left.\mathrm{mm}^{0.5}\right]\end{array}$ & & $\begin{array}{l}\text { Density } \\
{\left[\mathrm{g} / \mathrm{mm}^{3}\right]}\end{array}$ & $\begin{array}{l}\text { Electrical } \\
\text { resistivity } \\
{\left[10^{-6} \Omega \mathrm{m}\right]}\end{array}$ \\
\hline $10 \mathrm{wt} \% \mathrm{Co}$ & 2.2 & 1.8 & 4.2 & $1149 \pm 10$ & $>14.9 \pm 0.1$ & $578 \pm 6$ & 14.33 & 1.3 \\
\hline
\end{tabular}

The WC-10wt\%Co samples were machined and surface finished by wire-EDM or polishing. The polished surface variant was obtained by initially performing a grinding process using JF415DS grinding equipment (Jung, Göppingen, Germany) by means of a diamond abrasive wheel (type MD4075B55, Wendt Boart, Brussels, Belgium). The subsequent polishing operation was carried out with micrometer sized diamond paste up to optical finish. On the other hand, the wire-EDM surface finishing procedure was performed on a ROBOFIL 2000 (Charmilles Technologies, Switzerland) in de-ionized water (dielectric conductivity 11 $\mu \mathrm{S} / \mathrm{cm}$ ), using brass (CuZn37) wire electrode with diameter $0.25 \mathrm{~mm}$ and tensile strength $500 \mathrm{MPa}$. In this paper, the rough and finest EDM surface finishes E2 and E24, respectively, were selected for sliding wear experiments. The corresponding wire-EDM settings are listed in Table 2. Additional information on the wireEDM operation of the composites is given in [7,8].

Table 2. Device setting and parameters for rough and finer cutting regimes

\begin{tabular}{|l|c|c|}
\hline Wire-EDM regime & E2 & E24 \\
\hline Cut & Rough & Fine \\
\hline Open voltage $[\mathrm{V}]$ & -80 & 120 \\
\hline Pulse duration, $\mathrm{t}_{\mathrm{e}}[\mathrm{ms}]$ & 2.1 & 0.4 \\
\hline Pulse interval, $\mathrm{t}_{\mathrm{o}}[\mathrm{ms}]$ & 10 & 0.6 \\
\hline Reference servo voltage Aj [v] & 46 & 0 \\
\hline Pulse ignition hieght IAL [A] & 10 & 6 \\
\hline Flushing pressure [bar] & 15 & 0 \\
\hline Wire tension [N] & 1 & 1 \\
\hline Wire winding speed [m/min] & 9.6 & 8 \\
\hline
\end{tabular}

The surface roughness of the WC-Co cemented carbide with wire-EDM and polished surface finish was measured according to the ISO 4288 standard. The resulting Ra roughness values are summarized in Table. 3. Amongst the wire-EDM'ed composites, the highest roughness level is encountered with E2, whereas polished specimens are discerned to display the smoothest surface. 
Table 3. Surface roughness of polished, rough and fine wire-EDM'ed cemented carbide

\begin{tabular}{|l|c|c|c|}
\hline Surface finish & Polishing & E2 & E24 \\
\hline \hline$R_{a}(\mu \mathrm{m})$ & $\leq 0.02$ & 2.08 & 0.15 \\
\hline
\end{tabular}

Sliding wear testing was conducted using two different configurations: (i) a Plint TE77 machine with linear reciprocating pin-on-plate contact according to the ASTM G133 standard, and (ii) a CSM tribometer with rotating pin-on-disk contact in accordance with the ASTM G99-95a standard, respectively. Each wear experiment was performed in unlubricated conditions and in ambient air, i.e., $23 \pm 1$ and $60 \pm 1 \%$ relative humidity. Schematic illustrations of the applied linearly reciprocating pin-on-flat and rotating pin-on-disk sliding wear system are outlined in Figure 1.

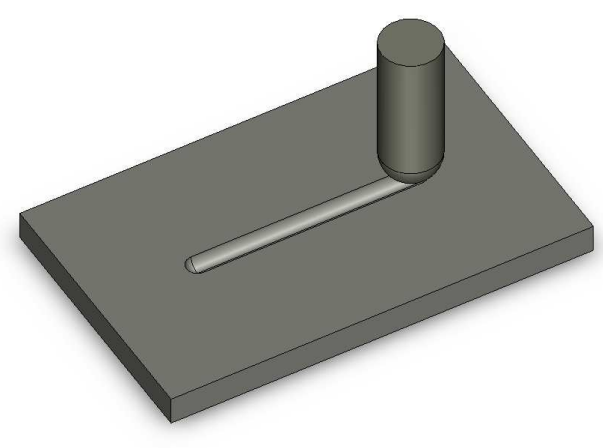

(A)

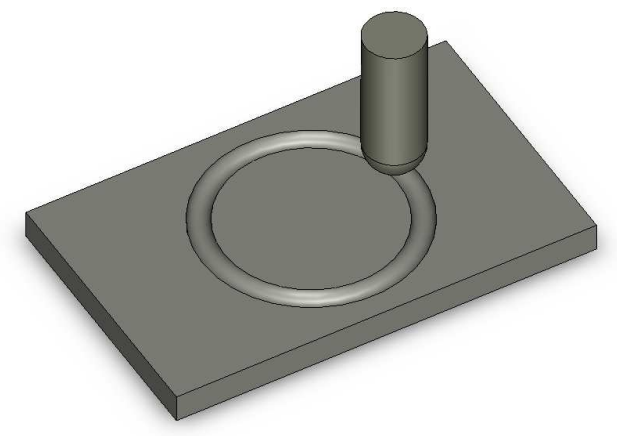

(B)

Figure 1. Geometric configuration of A) reciprocating and B) rotating sliding test.

The pin material was a WC-6wt\%Co cemented carbide (CERATIZIT grade MG12). The radius of the hemisphere was $4.04 \mathrm{~mm}$, with an $R_{a}$ and $R_{t}$ surface roughness of $0.35 \mu \mathrm{m}$ and $2.68 \mu \mathrm{m}$, respectively. The pin material displays an E-modulus of $609 \mathrm{GPa}$, a Vickers hardness $\mathrm{HV} 10$ of $1913 \mathrm{~kg} / \mathrm{mm}^{2}$, a compressive strength of $7.2 \mathrm{GPa}$ and fracture toughness $\mathrm{K}_{\mathrm{IC}, 10 \mathrm{~kg}}$ of $8.4 \mathrm{MPa} \mathrm{m}^{1 / 2}$. The counter plate samples were made of WC-10wt\%Co cemented carbide and displayed dimensions of $58 \mathrm{~mm} \times 38 \mathrm{~mm} \times 4 \mathrm{~mm}$. The test duration was associated with a sliding distance of $10 \mathrm{~km}$. Normal contact pressures of 1.76 and $2.08 \mathrm{GPa}$ were imposed, i.e., contact loads of $15 \mathrm{~N}$ and $25 \mathrm{~N}$, respectively, at a constant sliding velocity of $0.3 \mathrm{~m} / \mathrm{s}$.

\section{RESULTS AND DISCUSSION}

\subsection{Effect of wear particles on friction and wear response}

The influence of surface finishing operations and the imposed normal contact pressure on the tribological behavior of WC-10wt\%Co is examined in Fig. 2, which compares polished and wire-EDM'ed test samples in reciprocating and rotating sliding contact with respect to their dynamic coefficient of friction resulting from a $10 \mathrm{~km}$ sliding wear path, using WC-6wt\%Co pins at a speed of $0.3 \mathrm{~m} / \mathrm{s}$ together with normal pressures of 1.76 and $2.08 \mathrm{GPa}$. Each value is an average of at least three sliding experiments with identical test parameters. The standard deviation in friction coefficient between different samples of the same material was determined to be less than $5 \%$. The dynamic friction coefficient was discerned to vary within $0.45-$ 0.58. The differences in friction level between the distinctive surface finishing operations are quite pronounced. The dynamic friction coefficient is higher for wire-EDM surfaces compared to equivalent polished surface finish variant. Moreover, the highest friction levels are encountered with the roughest wireEDM surface finish variant, i.e., E2. For instance, reciprocating pin-on-plate sliding with a contact load of 15 $\mathrm{N}$ yielded a dynamic friction coefficient of 0.52 for surface finish variant $\mathrm{E} 2$, whereas dynamic friction coefficients of 0.47 and 0.45 were obtained for the finer wire-EDM step E24 and polishing, respectively. Amongst the various surface finishes and imposed normal contact pressures the WC-10wt\%Co specimens are found to yield higher friction coefficient on rotating sliding compared to the reciprocating sliding motion. Within the range of imposed contact pressures, the dynamic coefficient of friction is noticed to vary significantly. Indeed, raising the contact load is discerned to decrease the friction level. 


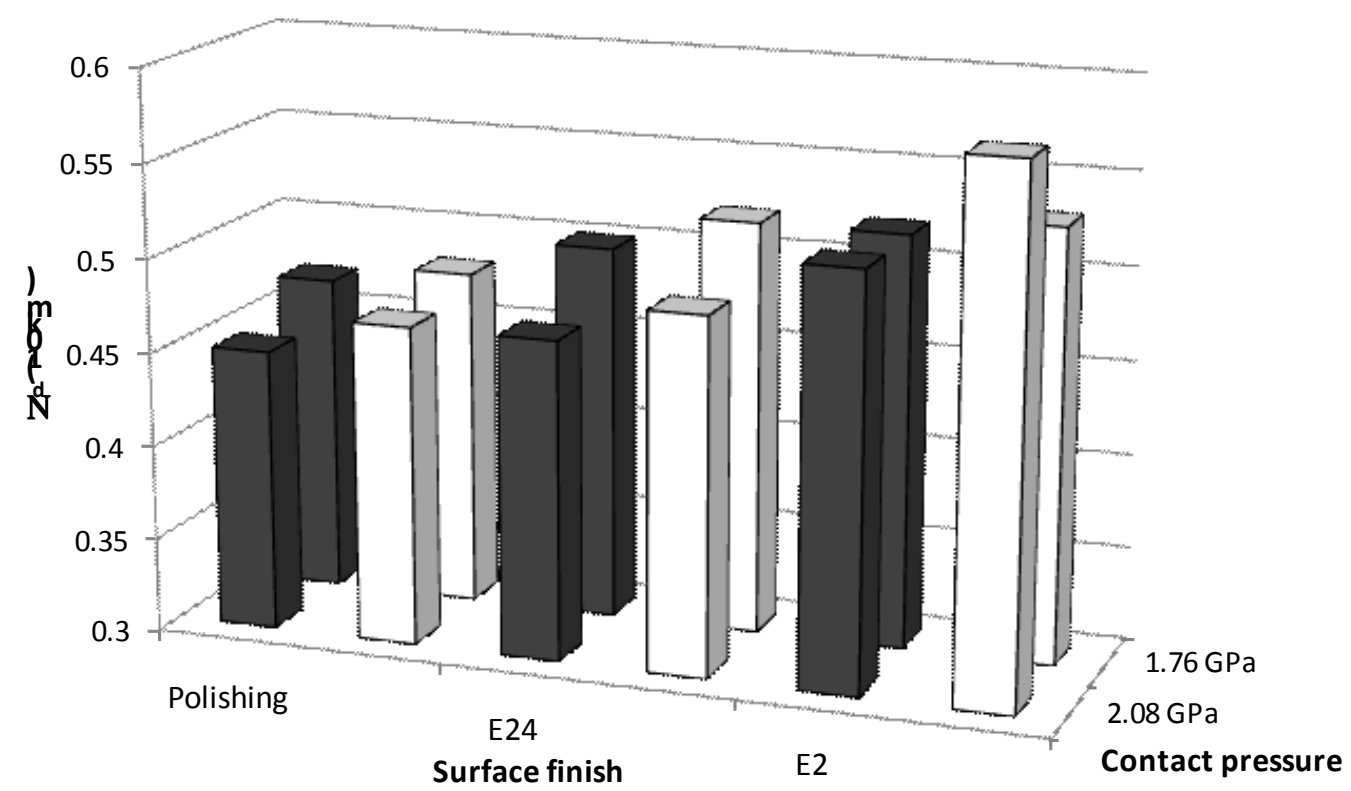

- Reciprocating $\square$ Rotating

Figure 2. Dynamic friction coefficient as a function of surface finishing operation for WC-10wt\%Co slid at $0.3 \mathrm{~m} / \mathrm{s}$ with 15 and $25 \mathrm{~N}$ contact load against WC-6wt\%Co pins for $10 \mathrm{~km}$

The observed friction curves during the sliding wear tests increase rapidly throughout the first meters of sliding, subsequently decline and increase towards an equilibrium situation (after running-in), in which fluctuation in friction are considerably smaller in reciprocating sliding motion. However, higher fluctuations in friction coefficient are observed in continuous rotating sliding tests. These instabilities can be explained in terms of continuous breaking and regenerating of micro-junctions at the contact surface. Additionally, it is apparent that the increase in friction coefficient can be attributed to the presence of wear particles at the sliding contact. In fact, there is a built-up of debris particles at the edge of the wear track that subsequently are pushed and clustering into the contact area, which are certainly related to small centrifugal force action on the particles as consequence of the rotating motion. This finding is in full agreement with the literature in the influence of wear particles, and the effect of reciprocating and rotating motion [9-13]. A visual inspection of worn surfaces after wear testing revealed the presence of wear debris accumulated at the edge of the wear tracks, but occasionally also within, along and adjacent to the wear tracks; see Figure 3.

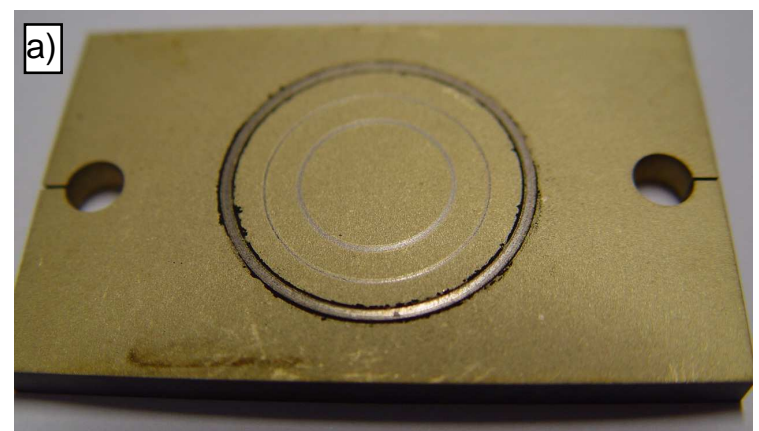



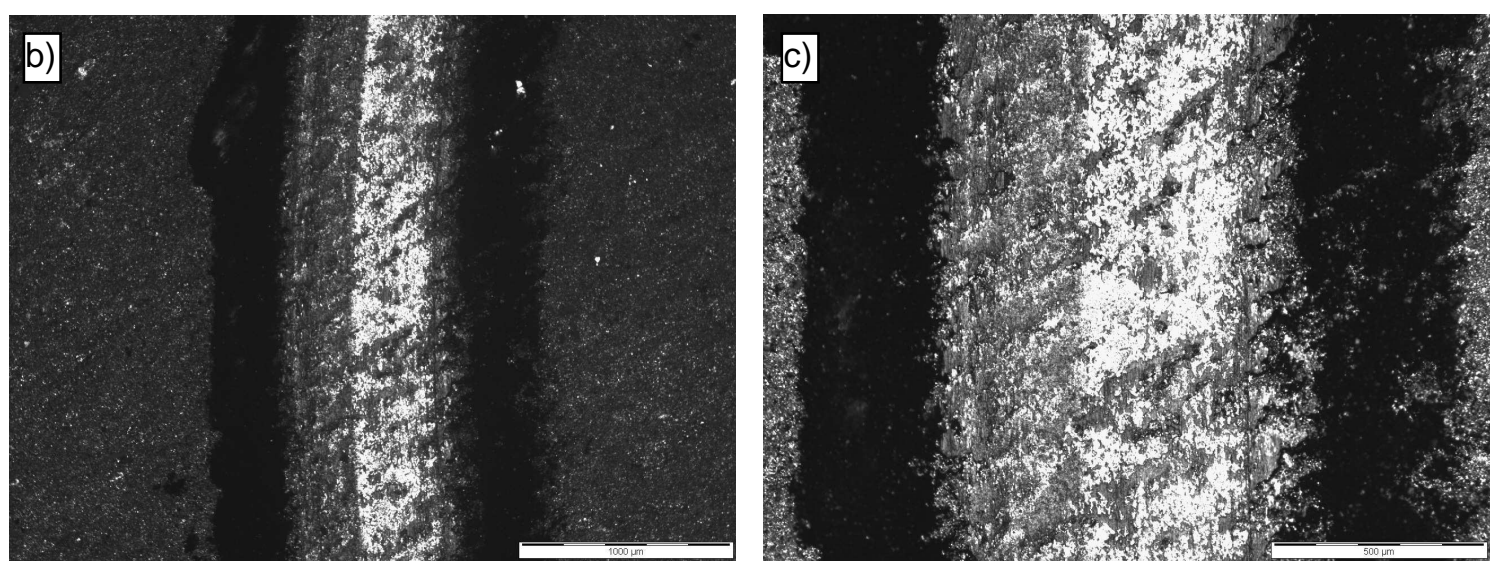

Figure 3. Surface view digital photograph (a) and micrographs with magnifications 50x (b) or 100x (c) on wear tracks of WC-10wt\%Co with surface finish E2 rotated against WC-6wt.\%Co for $10 \mathrm{~km}$ at a $0.3 \mathrm{~m} / \mathrm{s}$ sliding speed with mean Hertzian contact pressure 2.08GPa

Both reciprocating and rotating sliding wear experiments were continued up to a total sliding distance of 10 $\mathrm{km}$ ensuring that the wear processes had reached a 'steady state' condition. Wear volumes could be extracted from the generated wear tracks by means of profilometric surface scanning measurement. The wear volumes of WC-10wt\%Co cemented carbide as a function of surface finishing variant are compared in Figure 4. The wire-EDM'ed grades are characterized by higher wear volumes compared to their polished equivalents. The test samples evaluated in rotating sliding contact show higher wear damage compared to identical samples tested in reciprocating motion. A possible explanation for this finding could be that wear debris particles tend to break up more easily when the direction or the motion of the applied stress is reversed [11].

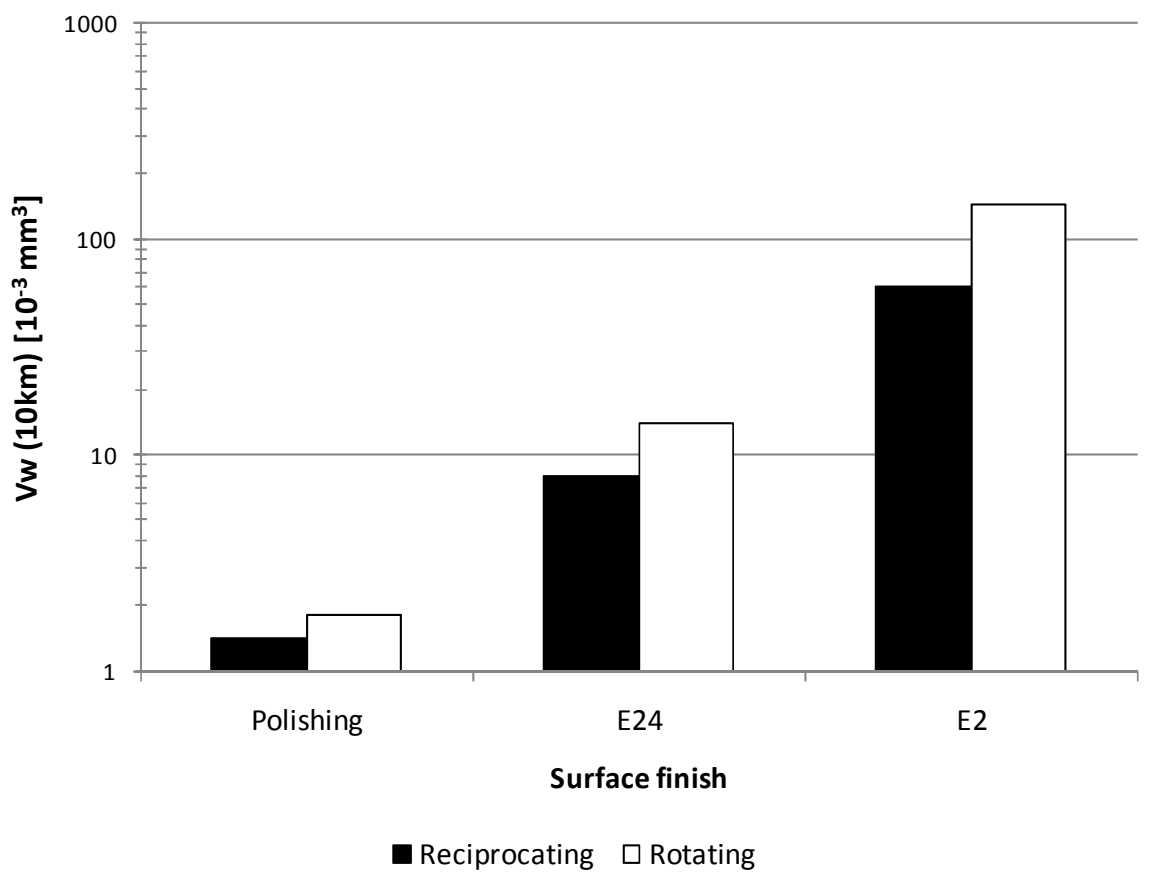

Figure 4. Wear volume as a function of surface finishing operation for WC- $10 \mathrm{wt} \% \mathrm{Co}$ slid at $0.3 \mathrm{~m} / \mathrm{s}$ with a mean Hertzian contact pressure of 1.76GPa against WC-6wt\%Co pins for $10 \mathrm{~km}$.

Whatever the underlying cause of the wear particle generation may be, the frictional characteristics of a sliding system are directly affected by the presence of such wear particles. However, the precise nature of the wear particle behaviour at the interface of a sliding contact needs to be further investigated by means of scanning electron microscopy (SEM) and energy dispersive X-ray (EDX) spectroscopy, for instance. 


\section{CONCLUSIONS}

Reciprocating and rotating wear testing of WC-10wt\%Co cemented carbide surface finished by sequential wire-EDM or polishing in dry sliding contact with WC-6wt\%Co counter body revealed significant increase of friction coefficient and wear level by wire-EDM. However, substantial improvements were obtained with finer-executed EDM finishing steps. Differences in tribological behaviour can be attributed to the wire-EDM induced recast layer, exhibiting lower wear resistance compared to the polished surface. Higher friction coefficient and wear volume was encountered in rotating sliding contact compared to linearly reciprocating conditions, which are believed to involve stronger interaction between wear debris at the sliding contact interface. The nature of the compound layer in the wear track and wear particles must be further elucidated by thorough investigation of cross-sectioned wear tracks.

\section{NOMENCLATURE}

$\begin{array}{lll}\mu_{d} & \text { Dynamic coefficient of friction } & - \\ V_{w} & \text { Wear volume } & \mathrm{mm}^{3} \\ \mathrm{R}_{\mathrm{a}} & \text { average roughness profile variation } & \mu \mathrm{m} \\ \mathrm{E} 2 & \text { rough wire-EDM step } & - \\ \mathrm{E} 24 & \text { fine wire-EDM step } & -\end{array}$

\section{ACKNOWLEDGEMENTS}

The authors would like to acknowledge the support of the Fund for Scientific Research Flanders (FWO, Grant No. G.0539.08) and the Flemish Institute for the promotion of Innovation by Science and Technology in industry (IWT, Grant No. GBOU-IWT-010071-SPARK). The authors gratefully recognize all the support, scientific contributions and stimulating collaboration from partners from Laboratory Soete, Ghent University (UGent) and Catholic University of Leuven (K.U.Leuven). Authors are also thankful to CERATIZIT for supplying the pins and hardmetals.

\section{REFERENCES}

[1] Q. Yang, T. Senda, N. Kotani, and A. Hirose, Sliding wear behavior and tribofilm formation of ceramics at high temperatures. Surface and Coatings Technology, 2004. 184(2-3): p. 270-277.

[2] Zhengui, Y., Stiglich, J.J., Sudarshan, T.S.: WC-Co enjoys proud history and bright future. Metal Powder Report 53(2), 32-36 (1998)

[3] K. Bonny, P. De Baets, Y. Perez et al, Friction and wear characteristics of WC-Co cemented carbides in dry reciprocating sliding contact, Wear 268 (2010) 1504-1517.

[4] Y. Perez, K. Bonny, O. Malek P. De Baets et al, Tribological behavior of wire-EDM'ed ZrO2-composites and cemented carbides, Sustainable Construction and Design (2010).

[5] Bonny, K., et al., Influence of electrical discharge machining on the reciprocating sliding wear response of WC-Co cemented carbides. Wear, 2009. 266(1-2): p. 84-95.

[6] Shetty, D. K., Wright, I. G., Mincer, P. N. and Clauer, A. H. (1985), Indentation Fracture of WC-Co Cermets, Journal of Materials Science 20, 5, pp 1873-1882.

[7] Bonny K, De Baets $P$, Vleugels J, Van der Biest O, Lauwers B, et al. EDM machinability and dry sliding friction of WC-Co cemented carbides. International Journal of Manufacturing Research 2009;4(4):375394.

[8] K. Bonny, P. De Baets, J. Vleugels, A. Salehi, O. Van der Biest, B. Lauwers, and W. Liu, EDM machinability and frictional behavior of ZrO2-WC composites. International Journal of Advanced Manufacturing Technology, 2009. 41(11-12): p. 1085-1093.

[9] Peter J. Blau, Matthew Walukas. Sliding friction and wear of magnesium alloy AZ91D produced by two different methods. Tribology International 33 (2000) 573-579. 
[10] Etsuo Marui, Hiroki Endo. Effect of reciprocating and unidirectional sliding motion on the friction and wear of copper on steel. Wear 249 (2001) 582-591.

[11]D.H. Hwang, D.E. Kim, S.J. Lee. Influence of wear particle interaction in the sliding interface on friction of metals. Wear 225-229 (1999) 427-439.

[12]D. Odabas, S. Su. A comparison of the reciprocating and continuous two-body abrasive wear behavior of solution-treated and age-hardened 2014 Al alloy. Wear 208 (1997) 25-35.

[13] Marcia M. Maru and Deniol K. Tanaka. Influence of Loading, Contamination and Additive on the Wear of a Metallic Pair under Rotating and Reciprocating Lubricated Sliding. J. of the Braz. Soc. of Mech. Sci. \& Eng. July-September 2006, Vol. XXVIII, No. 3. 278 - 285. 